\title{
Serviço pós-venda e fidelização de clientes: estudo de caso numa Farmácia Magistral
}

Post-sales service and customer loyalty: case study in a Mastercard Pharmacy

Sayure Brito ${ }^{1}$

${ }^{1}$ E-mail: $\underline{\text { sayurebrito@gmail.com }}$

\begin{abstract}
Resumo: No mercado atual, o serviço de pós-venda pode ser considerado um diferencial competitivo capaz de ajudar as empresas na fidelização dos seus clientes. Diante do grande número de farmácias de manipulação existentes, as farmácias magistrais buscam a cada dia um diferencial competitivo para a retenção de clientes, já que, somente, oferecer medicamentos com valores acessíveis ou produtos de qualidade não contribui mais para atrair novos clientes ou manter os já existentes. O intuito deste trabalho foi avaliar como o serviço de pós-venda pode contribuir na fidelização e retenção de clientes de uma farmácia de manipulação, compreendendo a sua utilização como ferramenta de apoio aos negócios. Para a mensuração dos resultados, utilizou-se a abordagem quantitativa por meio da pesquisa descritiva e estudo de caso. Para a coleta de dados, foi utilizado um questionário estruturado aplicado aos clientes da organização. Os resultados apresentados demonstraram que o consumidor atual valoriza e tende a preferir as organizações que utilizam serviços de pós-venda.
\end{abstract}

Palavras-chave: Pós-venda; Marketing de Relacionamento; Fidelização.

\begin{abstract}
In the current market, the after-sales service can be considered a competitive differential capable of helping companies in the loyalty of their customers. Faced with the large number of existing pharmacies, magistrate pharmacies are seeking a competitive differential for customer retention, since only offering affordable medicines or quality products no longer contributes to attracting new clients or maintaining the existing ones. The purpose of this study was to evaluate how the aftersales service can contribute to the loyalty and retention of customers of a pharmacy of manipulation, including its use as a tool to support business. To measure the results, the quantitative approach was used, through descriptive research and case study. For the data collection, a structured questionnaire was used, applied to the clients of the organization. The results presented demonstrate that the current consumer values and tends to prefer organizations that use after-sales services
\end{abstract}

Keywords: After-sales; Relationship Marketing; Loyalty. 


\section{pontěditora}

\section{Introdução}

No mercado atual percebe-se que a cada dia as organizações estão em busca de aprimoramento das suas atividades. Isso deve-se ao mercado consumidor, que vem demonstrando, cada vez mais, um elevado grau de exigência, requerendo das empresas, muito esforço para se manterem ativas no mercado. "Muitas empresas ainda planeiam seus produtos sem o input do consumidor, apenas para encontrá-los, depois, rejeitados pelo mercado. Esquecem os consumidores após a venda, para perdê-los, depois, aos concorrentes" (KOTLER, 1998, p. 27).

No meio a tanta concorrência, as organizações devem recorrer a estratégias para fidelizar os seus clientes. A rivalidade entre as empresas está cada dia mais acirrada. $\mathrm{O}$ consumidor, por sua vez, apresenta-se mais informado sobre as suas escolhas, não sendo considerado apenas a preferência de um produto/serviço pelo seu preço ou qualidade, mas também, a influência da organização em contribuir para sua escolha.

Assim como qualquer outro ramo de atividade, as farmácias de manipulação também sofrem a pressão dos seus concorrentes. O crescimento tecnológico proporcionou à indústria farmacêutica a disponibilização de medicamentos com valores mais acessíveis ao consumidor, fazendo com que as farmácias de manipulação buscassem outros meios de continuar as suas atividades, não dependendo somente da manipulação de fórmulas farmacêuticas, que até então, antes deste crescimento económico, era o meio que mais sustentava o ramo de suas atividades. Com isso, observou-se que somente a venda de medicamentos com valores mais acessíveis, ou produtos de qualidade, já não é suficiente para resistirem ao mercado. Diante da situação apresentada, chegou-se ao seguinte problema de pesquisa: a utilização da ferramenta pós-venda, poderia ser um meio de fidelizar o cliente?

Portanto, as empresas devem buscar a fidelização dos seus clientes, utilizando das ferramentas do marketing, respostas para os problemas que são cada vez mais constantes, analisando a real necessidade de desenvolver uma atividade em prol do desenvolvimento de relações com os clientes. A empresa, foco da pesquisa, consiste numa farmácia mineira, localizada na região centro-sul de Belo Horizonte, com atuação 


\section{pontěditora}

no ramo de farmácia de manipulação. Fundada em 2000, está no mercado há mais de 16 anos. Composta por 11 funcionários, além dos dois sócios que também trabalham na empresa, está estruturada da seguinte forma: cinco atendentes, uma farmacêutica e cinco colaboradores que atuam no setor de produção. Além da atividade central de manipulação de fórmulas farmacêuticas, ainda oferece uma linha própria de produtos cosméticos.

Por ser uma farmácia de manipulação, a legislação do setor não permite que essas empresas produzam seus produtos de revenda dentro do estabelecimento. Sendo assim, a empresa terceiriza toda a sua linha de produtos. Um dos sócios da empresa, com formação farmacêutica, bioquímica e industrial foi quem desenvolveu a linha de produtos cosméticos. Com foco no portfólio dos seus produtos, a empresa busca, como público-alvo, atender profissionais que atuam na área da estética, tendo em vista que, com este perfil de clientes, consiga expandir com mais facilidade a sua linha de produtos.

Assim, o objetivo geral deste trabalho consiste em analisar a relação do serviço pósvenda com os clientes e identificar se esse serviço, na percepção dos mesmos, contribui para a sua fidelização. Em decorrência do objetivo geral, os objetivos específicos foram: Levantar o perfil e necessidades dos clientes; avaliar o grau de satisfação do cliente em relação a diversos aspetos que envolvem o atendimento recebido; analisar a importância do serviço de pós-venda na perceção do cliente; analisar a vantagem de utilização do serviço pós-venda, como diferencial competitivo e apresentar propostas para a fidelização, se for o caso.

\section{Marketing}

O marketing representa uma das áreas da administração que em meio à economia tão assoladora, cada vez mais vem sendo estudado no mercado atual. Sendo o marketing um processo tão difundido mediante o cenário global, torna-se necessário definir o conceito de marketing a ser utilizado neste trabalho. Na visão de muitos, o marketing resume-se apenas em propaganda, limitando o seu campo de visão a esse pensamento, entendendo que, por meio da divulgação de um produto, serviço ou marca, estimula-se o interesse

$\mathrm{e}^{3}$ - Revista de Economia, Empresas e Empreendedores na CPLP | Volume 4 | Número 1 


\section{pontěditora}

de compra do consumidor. Porém, o marketing vai muito além disso.

Pode-se entender que o marketing consiste num processo empregado pelas organizações como meio de fazer negócios. De forma mais sucinta e objetiva, o marketing envolve clientes e a organização, sendo encarado como uma filosofia em que todos os membros da organização entendem o seu real conceito, como meio de alcançar os objetivos da empresa.

Ou seja, pode-se entender que o marketing significa um processo de planeamento e execução de funções disponíveis às empresas, a fim de criar trocas que satisfaçam metas individuais e organizacionais (CHURCHILL JR; PETER, 2012). Ainda segundo Churchill Jr. e Peter (2012), a essência do marketing está em desenvolver trocas voluntárias entre clientes e empresa, de modo que essas transações proporcionem benefícios para ambos.

O marketing envolve um conjunto diversificado de atividades direcionadas a ampla gama de bens, serviços e ideias. Tais atividades envolvem o desenvolvimento, a determinação de preço, a promoção e a distribuição de bens e serviços que atendam os desejos de consumidores e usuários industriais. Portanto, as atividades de marketing são importantíssimas tanto para as empresas individualmente como para a economia como um todo. (FUTRELL, 2003, p. 33)

Segundo Kotler (1998), o marketing constitui em um processo gerencial, pelos quais, indivíduos ou grupos obtêm o que necessitam por meio da criação, oferta ou troca de produtos de valor com os outros.

Para um melhor entendimento do conceito apresentado pelo autor, apresentam-se a seguir os quatro pilares que, segundo Kotler (1998), fundamenta o conceito de marketing:

- Mercado alvo: Nenhuma empresa pode operar em todos os mercados e satisfazer a todas às necessidades. Nem pode fazer um bom trabalho dentro de um mercado. As empresas trabalham melhor quando definem cuidadosamente o seu mercado alvo e preparam um programa de marketing sob medida.

$\mathrm{e}^{3}$ - Revista de Economia, Empresas e Empreendedores na CPLP | Volume 4 | Número 1 


\section{pontěditora}

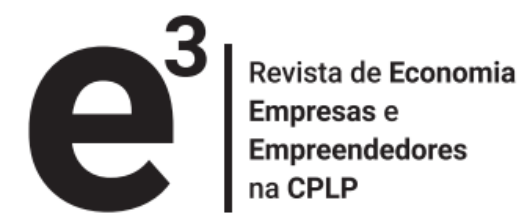

- Necessidades dos consumidores: Uma empresa pode definir o seu mercado alvo, mas falhar em conhecer plenamente as necessidades dos consumidores.

- Marketing integrado: Quando todos os departamentos da empresa trabalham em conjunto para tender aos interesses dos consumidores, o resultado é marketing integrado. Infelizmente, nem todos os funcionários são treinados e motivados a trabalhar para o consumidor.

- Rentabilidade: O propósito final do conceito de marketing é ajudar as organizações a atingir as suas metas. Nas organizações que visam o lucro, a chave não é atingir o lucro como tal, mas como subproduto de um bom trabalho. Uma empresa que melhor satisfaça as necessidades dos consumidores ganha mais dinheiro do que as suas concorrentes.

A partir destes levantamentos, pode-se compreender melhor o entendimento sobre o marketing e o seu papel no contexto das empresas, sendo considerado essencial em prol dos negócios oferecidos por uma organização. Nesse sentido, a próxima secção discute e importância do marketing de relacionamento para os resultados organizacionais.

\subsection{Marketing de relacionamento}

Nas últimas décadas, percebe-se que a visão das empresas, que encaram o marketing tradicional como meio de atrair novos clientes, vem ganhando uma nova visão. Genericamente, o marketing tradicional baseia-se na atração de novos clientes, desligando-se da retenção dos clientes já existentes (KOTLER; ARMSTRONG, 2015). Futrell (2003) diz que a ênfase do marketing de relacionamento está em direcionar o foco das vendas no cliente de hoje para a criação dos clientes de amanhã, fazendo com que as empresas pensem no cliente a longo prazo e não a curto prazo.

A organização que faz uso do marketing de relacionamento não está buscando uma simples venda ou transação. Ela se concentra num grande cliente para o qual gostaria de vender agora e no futuro. A empresa quer demonstrar ao cliente que ela dispõe dos recursos para atender as necessidades dele da melhor forma possivel, especialmente se puder ser criado um relacionamento comprometido. (FRUTELL, 2003, p. 42)

Por conta do avanço tecnológico, o aumento da competitividade expandiu-se ainda mais, levando as empresas a encarar um novo mercado. Com o avanço da tecnologia, não só 


\section{pontěditora}

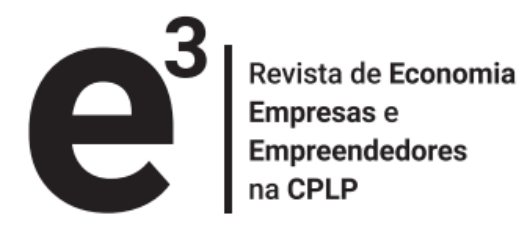

as empresas puderam ganhar forças e serem mais competitivas, mas também o cliente, que por sua vez, se tornou mais informando, ficando mais exigente em relação à escolha de compra.

Com isso, as empresas começaram a mudar as suas atitudes em relação à retenção de clientes, desencadeando o marketing de relacionamento. Kotler e Armstrong (2015) afirmam que o marketing de relacionamento busca criar, manter e aprimorar um relacionamento sólido com os clientes.

"A gestão do relacionamento com o cliente consiste em todo o processo de construir e manter relacionamentos lucrativos com os clientes entregando-lhes valor superior e satisfação" (KOTLER; ARMSTRONG, 2015, p. 12).

Para o marketing de relacionamento com o cliente, o principal propulsor da lucratividade da empresa é o valor agregado da sua base de clientes. Empresas vencedoras são as que mais adquirem, mantêm e desenvolvem clientes. Essas empresas aumentam o valor de sua base de clientes destacando-se na redução da taxa de perda de clientes, no aumento do período de relacionamento com o cliente, na elevação do potencial de receita e lucro de seus clientes, na transformação de clientes de baixo lucro em clientes mais lucrativos (ou na eliminação daqueles) e na concentração em clientes de alto valor. (KOTLER, 2005, p. 35)

O marketing de relacionamento apresenta-se como uma nova postura de interação entre a empresa e o cliente, gerando vínculos económicos e sociais entre as partes. " $\mathrm{O}$ marketing de relacionamento é baseado na premissa de que os clientes importantes precisam receber atenção contínua" (KOTLER, 1998, p. 619).

Contudo, as empresas estão percebendo que manter vínculos com os seus clientes significa um diferencial no sentido de manterem-se mais competitivas no mercado. $\mathrm{O}$ relacionamento com o cliente desencadeia uma corrente de valor ao cliente, fundamentando um relacionamento de longo prazo. "As empresas de hoje constroem relacionamentos mais profundos, diretos e duradouros com os clientes mais cuidadosamente selecionados" (KOTLER; ARMSTRONG, 2015, p. 16). Frutell (2003) menciona os três níveis do marketing de relacionamento com o cliente, fundamentando assim, este conceito.

- Vendas da transação única: Os clientes compram e não voltam a ser contactados. 


\section{pontěditora}

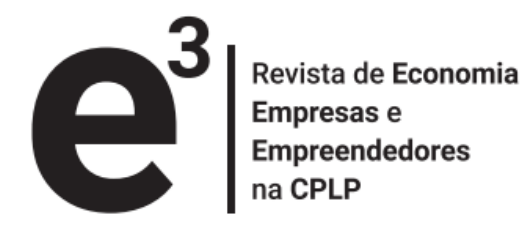

- Vendas de relacionamento: A empresa entra em contacto com os clientes após a compra para verificar se eles estão satisfeitos e se tem necessidades futuras.

- Parceria: A empresa trabalha continuamente no sentido de melhorar as operações, as vendas e o lucro dos seus clientes.

Nesse sentido, Futrell (2003) menciona que o marketing de relacionamento deve concentra-se na transação, em fazer a venda e acompanhar o serviço de pós-venda junto ao cliente.

A empresa deve relacionar-se ao cliente para verificar a satisfação com a compra.

Na próxima secção será abordado o tema das estratégias ligadas aos serviços pós-venda.

\subsection{Serviços de pós-venda}

O surgimento do serviço pós-venda relaciona-se com algumas particularidades da teoria do marketing, pois a prática de procurar manter o cliente fiel a uma empresa baseia-se no relacionamento com o cliente.

Atualmente, os clientes não procuram empresas que prestam o melhor serviço ou vendem os melhores produtos, para além disso, buscam empresas que lhes proporcionam junto ao serviço ou produto, a satisfação de si mesmo em comprar algo naquele ambiente escolhido.

"De nada adianta apenas vender e vender. É preciso mais do que isso para conquistar o cliente, impressioná-lo e torna-lo fiel" (CHIAVENATO, 2014, p. 241). Portanto, o objetivo do pós-venda consiste em gerar satisfação e fidelização ao cliente. Um cliente satisfeito poderá gerar novos clientes a uma organização, por meio de comentários positivos entre amigos e familiares.

À medida que a organização transmite confiança ao cliente, o mesmo se sente mais disposto a comprar novos produtos pela empresa. Sendo assim, o esforço na retenção de clientes, permite à redução de despesas, em que a mesma poderá reduzir os custos com propagandas e promoções de venda, buscando atrair novos clientes ou manter os clientes já existentes. 


\section{pontěditora}

A empresa precisa dedicar-se ao relacionamento posterior à venda. Com isso, manterá o cliente satisfeito, garantindo o seu retorno para uma próxima compra e estimulando a aquisição de produtos da mesma marca (BARRETO; CRESCITELLI, 2013).

Para Chiavenato (2014), o serviço de pós-venda abrange todas as atividades posteriores à venda, considerando parte imprescindível do processo de venda. Ou seja, o relacionamento pós-venda gera valor ao cliente, fazendo com que o mesmo crie uma corrente de compromisso com a empresa, gerando uma vida inteira de compras.

Da mesma maneira, como toda e qualquer empresa faz um seguimento (Follow-up) de suas compras corporativas, o consumidor costuma fazer o mesmo. $O$ agendamento da entrega daquilo que foi vendido, os serviços de assistência técnica, a resolução de possiveis problemas que independem do cliente e escapam ao seu controle, e a certeza de que as expectativas do cliente estão sendo plenamente satisfeitas são aspectos importantes no pós-venda, que influenciam poderosamente os hábitos e as decisões futuras de compra por parte do consumidor. (CHIAVENATO, 2014, p. 244)

O serviço de pós-venda pode proporcionar às empresas uma maior competitividade no mercado, a partir do momento que se procura conhecer melhor o seu cliente, como meio de mantê-lo na sua carteira de consumidor. As empresas, ao mesmo tempo, geram satisfação ao cliente, dando-lhe suporte ao serviço de pós compra, superando assim as suas expetativas e contribuindo com este feedback sobre a venda, estratégias para as empresas definirem com maior prontidão, o seu segmento de clientes, conhecendo-os individualmente.

Para Chiavenato (2014, p. 244), “A pós-venda deve ser encarada como um aspecto tão importante quanto à própria venda, da mesma forma como a eficiência deve ser sempre acompanhada pela eficácia".

Tendo em vista a necessidade do desenvolvimento de estratégias que aumentem a eficiência e eficácia, conforme defendido por Chiavenato (2014), na secção seguinte será tratado o tema da satisfação do cliente como estratégia para sua retenção. 


\section{pontěditora}

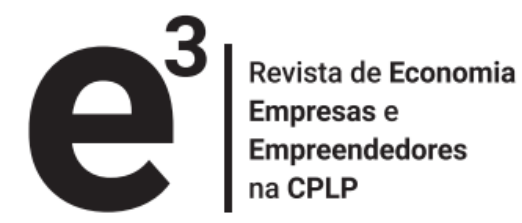

\subsection{Satisfação dos clientes}

Os desafios das organizações não estão ligados somente a planear, dirigir e controlar de maneira eficiente e eficaz os negócios da empresa. As empresas estão procurando dar uma maior atenção aos seus clientes, preocupando-se em satisfazer as suas necessidades e desejos.

Manter os clientes fiéis a uma empresa, nos dias atuais, tem sido uma missão cada vez mais difícil, pois os clientes apresentam-se cada vez mais exigentes, e com a concorrência acirrada, leva a sua retenção aquelas que melhor os satisfazer. Diante deste cenário, pode-se compreender que a existência das empresas gira em torno da satisfação do consumidor.

Todo o esforço mercadológico gira em torno da satisfação do consumidor. A pesquisa de marketing, a concepção e o desenvolvimento de produtos, com a sua definição de preço, distribuição e promoção, visam essencialmente à satisfação de necessidades ou desejos dos compradores, auferindo, como consequência da troca, o lucro almejado para a sustentabilidade do negócio. (SAMARA; MORSCH, 2005, p. 204)

"A satisfação do comprador após a realização da compra depende do desempenho da oferta em relação às suas expectativas" (KOTLER; KELLER, 2006, p. 142). O cliente agrega valor à sua decisão de compra, com base no que recebe da empresa. Em função disso, Kotler e Keller (2006) levam a compreender que a chance do cliente retornar a fazer outra compra na empresa dependerá se a empresa alcançou ou não essa expetativa de valor desse mesmo cliente.

A satisfação do cliente consiste na sensação de agrado que ele sente ao adquirir um produto/serviço. "Uma empresa deve proporcionar aos clientes uma satisfação maior que os custos que ela lhes solicita para adquirir o produto (ou serviço)" (SAMARA; MORSCH, 2005, p. 203).

Os clientes criam expectativas a partir do momento que sentem necessidades ou problemas que podem ser resolvidos por meio de um produto ou serviço. Com isso, suas expetativas são resultados que vão além do produto ou serviço tomados isoladamente. Ao se obter uma expetativa não esperada, isso, gera satisfação ao cliente.

Futrell (2003) ressalta que a satisfação do cliente está ligada às expetativas atendidas.

$\mathrm{e}^{3}$ - Revista de Economia, Empresas e Empreendedores na CPLP | Volume 4 | Número 1 


\section{pontěditora}

Refere-se também a sentimentos relacionados à compra. "A satisfação percebida com a compra é a sensação do cliente em relação a qualquer diferença entre o que é esperado e a experiência real da compra" (FUTRELL, 2003, p. 344).

Oferecer produtos e serviços que satisfaçam as necessidades dos clientes, exige aprofundamento das empresas em conhecer o cliente, tendo conhecimento sobre as expetativas que eles esperam. As empresas devem priorizar as expetativas do cliente, identificando as mudanças e se adequando para atendê-las.

A empresa deve avaliar a satisfação dos clientes com regularidade, pois a chave para reter clientes, está em satisfazê-los (KOTLER; KELLER, 2006). Quando o cliente se sente satisfeito com uma organização, ela pode esperar deste cliente um relacionamento duradouro, de longo prazo.

\subsection{Fidelização e retenção do cliente}

Atualmente, os clientes têm se apresentado mais difíceis de agradar, sendo mais inteligentes em relação aos diversos factores decisivos para fazer a escolha de compra e, além disso, estão mais conscientes em relação aos preços, perdoam menos e sofrem maior pressão da concorrência com ofertas iguais ou superiores. Com isso, o desafio em reter os clientes de hoje não consiste em deixá-los satisfeitos, tendo em vista que a concorrência pode fazer isso, o desafio consiste em conquistar clientes fiéis (KOTLER; KELLER, 2006).

Diante deste cenário, algumas organizações buscam métodos de atrair e reter clientes potenciais, a fim de criar vínculos de longo prazo, e para se criar um relacionamento duradouro, deve-se encontrar artifícios de fidelização e retenção deste cliente.

A fidelidade é um dos objetivos principais da ação do marketing: a intenção não é contar apenas com clientes eventuais, que fazem algumas compras vez ou outra; mas cativá-los de modo que sempre voltem e procurem manter-se vinculados à marca. (GARCIA, 2015, p. 31)

Barreto e Crescitelli (2013) afirmam que a fidelização dos clientes significa um dos principais objetivos do marketing de relacionamento, em que se percebe a importância

$\mathrm{e}^{3}$ - Revista de Economia, Empresas e Empreendedores na CPLP | Volume 4 | Número 1 
de entender o que leva o cliente a se tornar fiel, bem como a identificar a fidelidade do cliente depois de conquistada. "A identificação da fidelidade ou não de um cliente é um dos principais elementos de avaliação dos resultados de uma ação de relacionamento" (BARRETO; CRESCITELLI, 2013, p. 71).

Pode-se definir a fidelidade como a repetição de compra. Porém, isso não é o bastante para definição do tema, já que nem sempre o facto de um cliente repetir uma compra significa que está fidelizado. A fidelização vai muito além disso.

Manter clientes fiéis costuma sair mais barato que buscar um novo cliente a todo o tempo. Além disso, clientes fidelizados costumam gerar um importante retorno financeiro para as empresas. Diante disso, toda a instituição deve acompanhar o nível de fidelidade dos seus clientes (GARCIA, 2015).

Atrair e reter clientes pode ser uma tarefa difícil. Com frequência, os clientes têm a sua disposição uma grande variedade de produtos e serviços para escolher. $O$ cliente compra da empresa que lhe oferece o mais alto valor percebido pelo cliente - a avaliação que o cliente faz da diferença entre todos os benefícios e todos os custos de uma oferta ao mercado em relação às ofertas concorrentes. (KOTLER; ARMSTRONG, 2015, p. 13)

Muitas vezes, as empresas confundem a satisfação do cliente como sinónimo de fidelização. Nem sempre uma acarreta a outra. Pode ocorrer um consumidor comprar algo numa empresa, não por se sentir fidelizado, mas por conveniência. Com isso, Garcia (2015) diz que a fidelidade de um cliente não pode ter como base apenas a satisfação do mesmo.

Torna-se necessário encontrar meios de identificar se o cliente se sente fidelizado ou não com o serviço ou produto disponibilizado pela empresa. "Existem clientes satisfeitos que não são fiéis, mas existem também clientes insatisfeitos que o são" (GARCIA, 2015, p. 31).

Assim, observa-se que muitos clientes compram de empresas por que se sentem satisfeitos com a prestação do serviço, ou do produto. Isso não leva a crer que o cliente seja fiel àquela empresa. Ele pode sentir-se satisfeito em comprar determinada marca, 


\section{pontěditora}

mas sofre influência de outras marcas, fazendo com que utilize outros produtos/serviços. Por conta disso, Garcia (2015, p. 32) leva a compreender que "esses fatores mostram que é preciso medir a fidelidade desvinculando-a da satisfação".

Kotler e Armstrong (2015) afirmam que uma boa gestão de relacionamento com o cliente, gera o encantamento do mesmo. Em função disso, torna-se essencial que as empresas procurem meios de fidelização do cliente. $\mathrm{O}$ cliente cativado pode permanecer fiel, levando a outros consumidores, ideias favoráveis sobre a empresa e seus produtos.

Estudos mostram grandes diferenças entre a fidelidade de clientes que estão menos satisfeitos, relativamente satisfeitos e completamente satisfeitos. Mesmo uma pequena queda da plena satisfação pode criar uma enorme queda na "fidelidade". Assim, o objetivo da gestão de relacionamento com o cliente não é apenas gerar a sua satisfação, mas também o seu encantamento. (KOTLER; ARMOSTRONG, 2015, p. 20)

Portanto, as empresas percebem que perder um cliente representa mais do que perder uma única venda, significa perder o valor de todas as compras que um cliente faria ao longo de um relacionamento de fidelidade (KOTLER; ARMSTRONG, 2015).

\section{Metodologia}

Pode-se definir pesquisa como o "procedimento racional e sistemático que tem como objetivo proporcionar respostas aos problemas que são propostos" (GIL, 2009, p. 17). Para Vergara (2008), os tipos de pesquisa podem ser definidos por dois critérios básicos: quanto aos fins e quanto aos meios.

Sendo assim, quanto aos fins foi realizada uma pesquisa descritiva, sendo esta a técnica de pesquisa escolhida que acreditou-se ser a melhor que apresentaria os dados a serem averiguados, permitindo analisar o serviço de pós-venda como ferramenta de fidelização dos clientes da farmácia de manipulação.

Os estudos descritivos, também chamados pesquisas Ad Hoc, como diz o próprio nome, procuram descrever situações de mercado a partir de dados primários, obtidos originalmente por meio de entrevistas pessoais ou discussões em grupo, relacionando e confirmando as hipóteses levantadas na definição do problema de pesquisa. (SAMARA; BARROS, 2006, p.50)

A pesquisa descritiva objetiva descreve as características de determinada população ou 


\section{pontěditora}

fenómeno, ou estabelecimento de relações entre variáveis (KAUARK; MANHÃES; MEDEIROS, 2010). As características que melhor a define consistem na adoção de técnicas padronizadas de coletas de dados tais como a utilização de questionários e observação sistémica (GIL, 2009).

Segundo Gil (2009), a pesquisa descritiva pode ir além da simples identificação da existência de relações entre variáveis, pretendendo determinar a natureza dessa relação. Vergara (2000, p. 47) "argumenta que a pesquisa descritiva expõe as características de determinada população ou fenômeno, estabelece correlações entre variáveis e define sua natureza”.

Quanto aos meios, utilizou-se o estudo de caso com abordagem quantitativa. Para Gil (2009), o estudo de caso consiste no estudo profundo e árduo de um ou poucos objetivos, de forma que permita o amplo e detalhado conhecimento. Gil (2009) afirma que os propósitos do estudo de caso não estão em propor conhecimento preciso das características de uma população, mas sobretudo, em proporcionar uma visão global do problema ou identificar possíveis factores que influenciam ou são por ele influenciados.

O questionário estruturado foi o instrumento adotado para a coleta de dados, buscando analisar a perceção dos participantes sobre a importância do serviço de pós-venda no processo de fidelização dos clientes, avaliando se a implantação de serviço pós-venda contribuirá em prol da fidelização do cliente.

A amostra do estudo contou com a participação de 58 clientes da empresa que preencheram o questionário semiestruturado, composto por 15 questões, como instrumento adotado para a coleta de dados. "A amostragem é uma parcela conveniente selecionada do universo (população); é um subconjunto do universo" (MARCONI; LAKATOS, 2005, p. 165). Segundo Marconi e Lakatos (2002), "amostragem" não probabilística tem como característica principal não fazer uso de formas aleatórias de seleção, tendo sido esse tipo o adotado neste estudo.

Segundo Marconi e Lakatos (2005), após a coleta dos dados o passo seguinte consiste em elaborar e classificar estes elementos de forma sistemática. Tendo em vista a 


\section{pontěditora}

abordagem quantitativa, os dados foram analisados estatisticamente, sendo apresentados por meio de gráficos.

\section{Apresentação e discussão dos resultados}

Este trabalho utilizou a técnica de pesquisa do tipo descritiva, com o intuito de identificar por meio da análise das características da população em estudo, se o serviço de pós-venda pode ser um meio de fidelização dos clientes da empresa pesquisada. Estão apresentados a seguir os dados mais relevantes da pesquisa. Buscou-se analisar o diferencial competitivo que a empresa pode alcançar por meio de clientes fidelizados.

Referindo-se ao perfil sócio económico dos clientes da empresa, a pesquisa apresentou que o perfil predominante consiste em pessoas do sexo feminino, correspondente a mais de $90 \%$ dos pesquisados. Relativo à faixa etária, $88 \%$ dos entrevistados possuem idade entre 21 e 40 anos. A pesquisa demonstrou que 43,1\% dos entrevistados possuem renda familiar acima de $\mathrm{R} \$ 5.000,00$, indicando que os clientes da farmácia possuem um poder aquisitivo de nível mais elevado.

A seguir, apresenta-se os resultados considerados mais relevantes para a análise dos dados coletados e esclarecimento do problema de pesquisa do estudo.

O Gráfico 1 apresenta a importância, na perceção do entrevistado, do serviço de pósvenda no processo de fidelização do cliente.

Gráfico 1 - Importância do serviço de pós-venda para a fidelização dos clientes

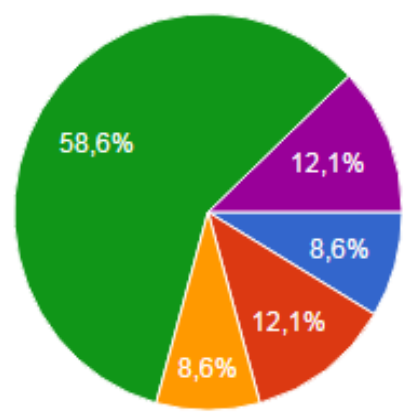

Concordo totalmente

Concordo parcialmente

Não concordo e não discordo

Discordo totalmente

Discordo parcialmente

Fonte: Dados da pesquisa (2017).

$\mathrm{e}^{3}$ - Revista de Economia, Empresas e Empreendedores na CPLP | Volume 4 | Número 1 


\section{pontěditora}

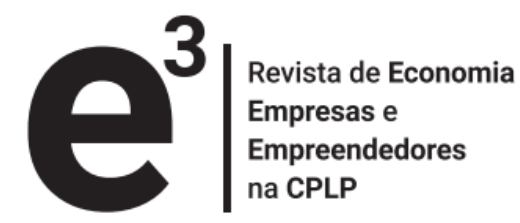

Observa-se no Gráfico 1 que 70,7\% dos clientes da empresa discordam totalmente ou parcialmente, que a utilização dos serviços de pós-venda tem pouca relevância em relação a sua fidelização. Com base neste resultado, pode-se concluir que grande parte dos clientes entrevistados consideram a ferramenta pós-venda um meio de fidelização importante. Sendo assim, nota-se que os clientes atuais tendem a priorizar as empresas que lhe dão atenção após o momento da compra, reforçando o entendimento de Kotler e Armstrong (2015) que aponta que a gestão do relacionamento com o cliente baseia-se em todo o processo de construir e manter relacionamentos lucrativos, em prol de lhe dispor valor superior e satisfação.

O Gráfico 2 exibe a perceção do entrevistado, em relação à sua opinião e à sua escolha em dar preferências a um bom atendimento ou ofertas e promoções da concorrência.

Gráfico 2 - Preferências dos entrevistados em relação à importância do atendimento recebido VS ofertas e promoções da concorrência.

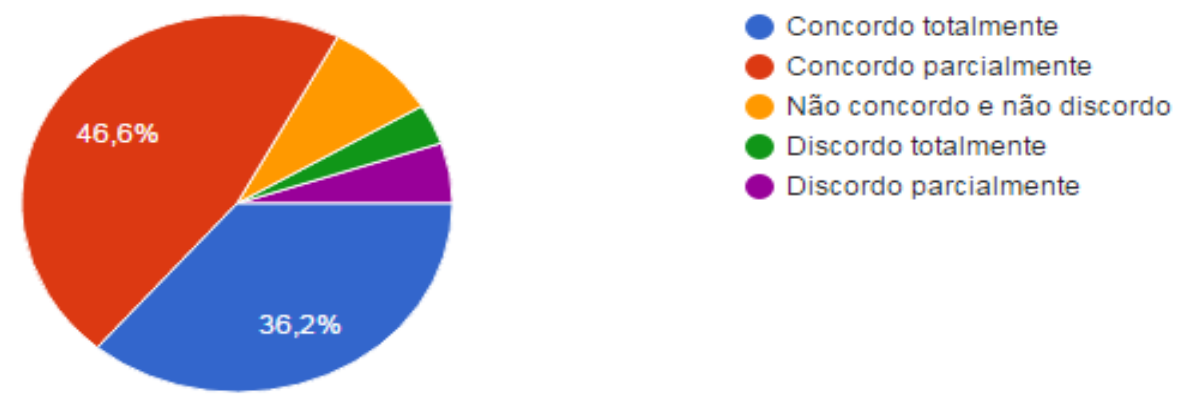

Fonte: Dados da pesquisa (2017).

Observa-se pelo Gráfico 2 que mais da metade dos clientes consideram que o bom atendimento supera o esforço da concorrência no que diz respeito às ofertas e promoções, tendo sido apontado por $82,8 \%$ dos pesquisados, concordando totalmente ou parcialmente com essa afirmação. Esse dado torna-se de grande relevância para a empresa em estudo, pois demostra a importância em se oferecer um bom atendimento aos seus clientes, corroborando a sugestão de Kotler e Armstrong (2015) quando afirmam que atrair e reter clientes não representa uma tarefa fácil para as organizações. 


\section{pontěditora}

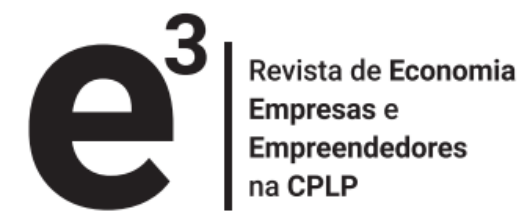

Com grande frequência, os clientes vêem ao seu redor uma grande variedade de produtos e serviços à sua escolha, onde a avaliação que o cliente faz da diferença entre os benefícios e todos os custos das ofertas oferecidas, em relação à oferta da concorrência, leva a sua escolha de compra à empresa que lhe dispor o mais alto valor percebido. Os autores ainda destacam que, por mais importante que seja um bom atendimento para atrair os clientes, considera-se ponderoso que as empresas tenham consciência que, somente isto, não é suficiente para a retenção do consumidor. Conforme Kotlere Armstrong (2015), as empresas devem procurar entregar maior valor ao cliente, fazendo com que o mesmo tenha encantamento pelo serviço prestado.

O Gráfico 3 apresenta a opinião dos entrevistados em relação à sua visão a respeito do serviço de pós-venda em termos de valor agregado ao produto.

Gráfico 3 - Serviço de pós-venda, capaz de agregar valor ao produto adquirido.

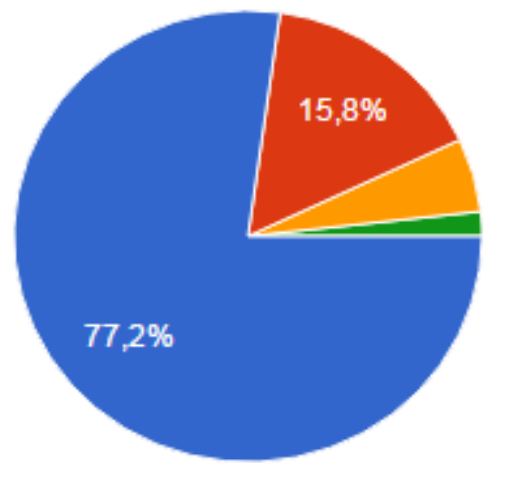

Concordo totalmente

Concordo parcialmente

Não concordo e não discordo

Discordo totalmente

Fonte: Dados da pesquisa (2017).

Percebe-se, na análise do Gráfico 3, que 93,0\% dos clientes concordam total ou parcialmente que o serviço de pós-venda pode agregar valor ao produto adquirido. Dessa maneira, pode-se anunciar que os clientes consideram um valor agregado às empresas que se recordam deles após o momento da compra. Na opinião de Futrell (2003), existem 3 níveis do marketing de relacionamento com o cliente, sendo estes: vendas da transação única, vendas de relacionamento e parceria; ressaltando que nas vendas de relacionamento, a empresa deve entrar em contacto com seus clientes após a compra, para averiguar a sua satisfação e se os mesmos possuem necessidades futuras. Sendo assim, o marketing de relacionamento deve concentrar-se em fazer a venda e 


\section{pontěditora}

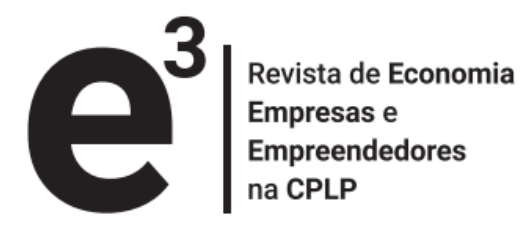

acompanhar o serviço de pós-venda junto ao cliente.

Para a empresa em estudo, que possui uma linha própria de produtos cosméticos, esse dado representa importância de destaque, contribuindo para a melhoria dos seus produtos comercializados. Uma vez que, ao utilizar o serviço de pós-venda junto ao cliente, a empresa pode obter sugestões de aperfeiçoamento para o produto adquirido pelo cliente.

O Gráfico 4 apresenta a sua avaliação do pesquisado sobre o contacto recebido após a realização da compra.

Gráfico 4 - Contato pós-venda após a realização da compra.

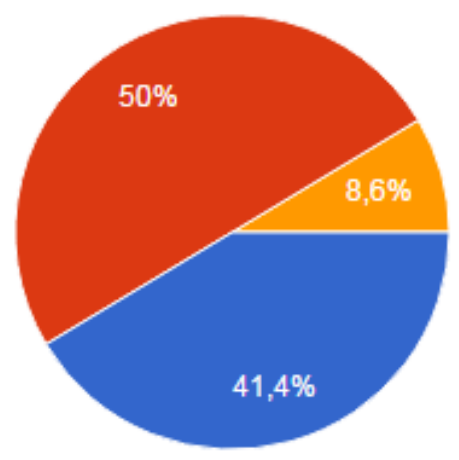

Muito importante

Importante

Pouco importante

Muito pouco importante

Fonte: Dados da pesquisa (2017).

Nota-se no Gráfico 4 que, na perceção do cliente, o contacto após a compra representa um factor importante ou muito importante no processo de fidelização, sendo este considerado por $91,4 \%$ dos respondentes. Reforçando o que já apontou Chiavenato (2014) quando sugeriu que o serviço de pós-venda abrange todas as atividades posteriores à venda, considerando parte imprescindível do processo de venda. Ou seja, o relacionamento pós-venda gera valor ao cliente, fazendo com que o mesmo crie uma corrente de compromisso com a empresa, gerando uma vida inteira de compras. Esse resultado demostra que quase $100 \%$ dos clientes pesquisados entendem a importância em obter o contacto após a realização da compra. Com isso, torna-se essencial que a empresa desenvolva um cronograma de contacto com os clientes ativos, como meio de alcançar a retenção destes.

$\mathrm{e}^{3}$ - Revista de Economia, Empresas e Empreendedores na CPLP | Volume 4 | Número 1 


\section{pontěditora}

O Gráfico 5 buscou avaliar o grau de satisfação dos clientes em relação ao atendimento recebido.

Gráfico 5 - Satisfação em relação ao atendimento recebido.

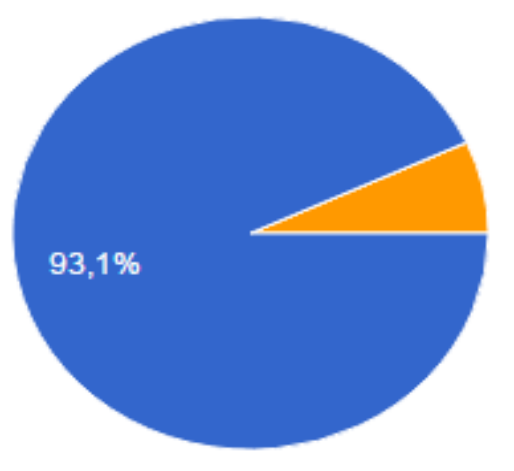

Satisfeito

Insatisfeito

Parcialmente satisfeito

Fonte: Dados da pesquisa (2017).

Observa-se no Gráfico 5 que 93,1\% dos clientes demostram satisfação com o atendimento recebido na empresa pesquisada, estando o restante $(6,9 \%)$ parcialmente satisfeito. Nota-se que, para Kotler e Keller (2006), a satisfação do consumidor após a realização da compra depende da execução da oferta em relação às suas expetativas, ressaltando que o cliente agrega valor na sua decisão de compra, com base no que recebe da empresa. Já Samara e Morsch (2005) declaram que a empresa deve comprometer-se com os clientes buscando proporcionar uma satisfação maior do que os custos que este teve para adquirir o produto/serviço. Contudo, a empresa não pode deixar de basear somente na satisfação do cliente diante desta demonstração. Com isso, nota-se que é preciso mais que um bom atendimento para reter um cliente. Satisfação não é sinónimo de retenção. A satisfação pode ser percebida pelo consumidor em diversos momentos, mas a retenção do cliente vai além de um bom atendimento ao satisfaze-lo.

No Gráfico 6 buscou-se identificar a opinião dos pesquisados relativamente às empresas que possuem serviços de pós-venda, considerando-se aquelas que utilizam essa ferramenta como vantagem competitiva aos negócios, e se estes, dão preferência a empresas que oferecem o serviço pós-venda. 


\section{pontěditora}

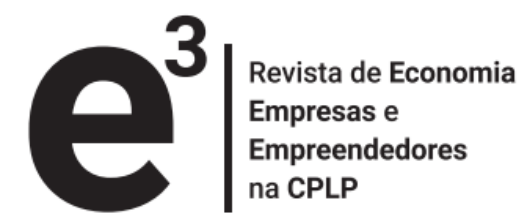

Gráfico 6 - Preferência dos clientes em relação às empresas que utilizam serviços de pós-venda.

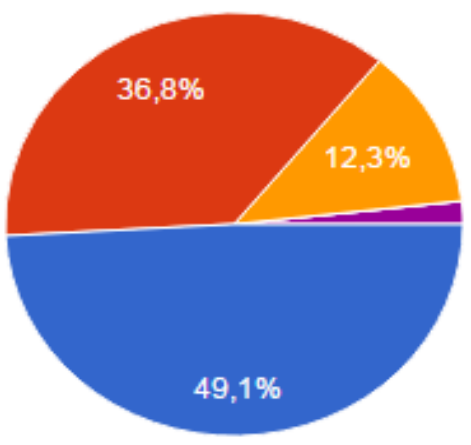

Concordo totalmente

Concordo parcialmente

Não concordo e não descordo

Discordo totalmente

Discordo parcialmente

Fonte: Dados da pesquisa (2017).

Os resultados expressos no Gráfico 6 apontam que 85,9\% dos clientes dão preferência a uma empresa que possui o serviço de pós-venda. Apenas 12,3\% diz-se indiferente a esse quesito e 1,8\% não considera o serviço com uma vantagem competitiva. Esse resultado evidencia que grande parte dos consumidores dão preferência às empresas que utilizam os serviços de pós-venda. Futrell (2003) menciona que o marketing de relacionamento não busca uma simples venda ou transação. As empresas que priorizam essa estratégia, concentram-se em clientes hoje, para garantirem o cliente de amanhã.

Dessa forma, as empresas devem demonstrar aos clientes que dispõem dos recursos para atender as suas necessidades da melhor maneira, principalmente se puder criar um relacionamento comprometido. Assim, os resultados apontam que os clientes enxergam que a ferramenta pós-venda pode ser um diferencial competitivo para as empresas que a utilizem. Ainda que o objetivo das organizações seja desenvolver clientes fiéis, a lealdade dos clientes não se apresenta tão resistente ao ponto de esquecerem o que a concorrência dispõe. Diante disso, o serviço de pós-venda pode ser relevante no sentido de identificar a perceção do cliente em relação à empresa e também à concorrência.

\section{Considerações finais}

O estudo procurou analisar a relação do serviço pós-venda com os clientes e identificar se esse serviço, na percepção dos clientes, contribui para a sua fidelização. Diante dos 


\section{pontěditora}

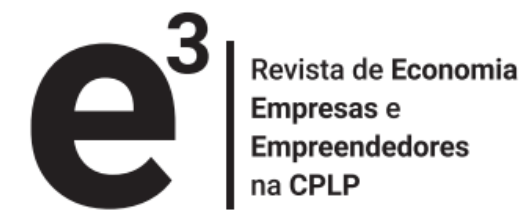

dados analisados, observou-se que os clientes dão preferência às organizações que os distinguem não apenas como consumidores, mas que procuram entender os seus desejos e necessidades, dando importância à sua opinião relativamente aos serviços e ao produto. Isso significa que o serviço de pós-venda representa uma ferramenta muito importante para as empresas, no sentido de dar ao cliente a oportunidade de retornar ofeedback que ele espera e, ao mesmo tempo, faz com que o cliente se sinta parte importante desse processo, levando-o à fidelização.

Em decorrência dos resultados, a pesquisa respondeu a todos os objetivos estabelecidos para o estudo, sendo possível identificar que a empresa possui clientes potenciais que contribuirão para o êxito futuro da organização, já que estes apresentaram-se satisfeitos com os serviços recebidos e com os produtos adquiridos. Além de certificar que os consumidores atuais dão preferência a empresas que utilizam estratégias baseadas no relacionamento com o cliente, percebendo essa estratégia como uma vantagem competitiva das organizações.

Desse modo, evidencia-se que os resultados manifestados reconhecem que os clientes priorizam as empresas que estabelecem um contacto de relação contínua, revelando ainda que os clientes vêem a utilização dos serviços de pós-venda como vantagem competitiva para o presente e futuro das organizações.

Desse modo, ressalta o entendimento que as organizações devem procurar conquistar o cliente de maneira estratégica e eficiente, buscando satisfazê-lo plenamente. Segundo Chiavenato (2014), a satisfação do cliente deve ser total, sendo reforçada antes, durante e após o processo da venda. Com base nos resultados da pesquisa, deduz-se que os clientes dão preferência às empresas que os dão assistência após a compra, reforçando a teoria dos autores pesquisados. Pode-se considerar que o serviço de pós-venda pode influenciar de forma significativa a fidelização dos clientes, sendo a ponte entre o cliente e a organização.

De modo a contribuir com a organização estudada, apresenta-se no final desse trabalho propostas de melhorias, baseando-se nos conceitos dos autores estudados e no conhecimento obtido por meio da análise de dados da pesquisa. 


\section{pontěditora}

Destaca-se que as principais contribuições do estudo consistem em conhecer a perceção dos clientes em relação ao tema da pesquisa e, assim, propor melhorias objetivando o aumento do nível de satisfação dos clientes, o que leva por consequência à sua fidelização e para o meio académico que poderá utilizar o trabalho como fonte de pesquisa e referência. Ressalta-se ainda que, por tratar-se de um estudo de caso, os resultados aqui descritos não devem ser generalizados a outras empresas do mesmo ou de diferentes segmentos.

Diante do exposto, apresenta-se a seguir as propostas recomendadas à empresa, considerando os resultados mais relevantes para esse trabalho.

\section{Quadro 1 - Recomendações}

\section{Recomendações}

\begin{tabular}{|c|l|}
\hline \hline Treinamento & $\begin{array}{l}\text { Executar treinamento à força de vendas, } \\
\text { para melhor capacitação de toda a equipa, } \\
\text { sendo de suma importância que os } \\
\text { vendedores tenham em vista a importância } \\
\text { de se prestar o serviço de pós-venda e } \\
\text { conheçam os objetivos estratégicos da } \\
\text { organização. }\end{array}$ \\
\hline Banco de dados & $\begin{array}{l}\text { Organizar o banco de dados de todos os } \\
\text { clientes ativos na empresa e, se possível, } \\
\text { resgatar os dados dos clientes inativos. É } \\
\text { importante enfatizar que, para empregar o } \\
\text { serviço de pós-venda, a empresa organize } \\
\text { o banco de dados de seus clientes da forma } \\
\text { mais legítima possível, para que, assim, } \\
\text { conheça os seus clientes de maneira mais } \\
\text { individual, de modo a estreitar o } \\
\text { relacionamento, mantendo-se ativa na } \\
\text { mente do consumidor. }\end{array}$ \\
\hline
\end{tabular}




\section{pontěditora}

\begin{tabular}{|c|l|}
\hline Estruturar ações & $\begin{array}{l}\text { Propõe-se verificar periodicamente o } \\
\text { banco de dados de todos os clientes, } \\
\text { utilizando-se desta informação, } \\
\text { sustentação para o contacto com o mesmo. }\end{array}$ \\
\hline Documentar ações & $\begin{array}{l}\text { Deve-se documentar cada ação ocorrida, } \\
\text { assim como utilizar-se destes resultados, } \\
\text { permitindo identificar os desejos dos } \\
\text { clientes e apresentar o que de facto } \\
\text { responderá à sua necessidade. }\end{array}$ \\
\hline
\end{tabular}

Fonte: Dados da pesquisa (2017).

\section{REFERÊNCIAS}

BARRETO Iná Futino; CRESCITELLI Edson. Marketing de relacionamento: como implantar e avaliar resultados. São Paulo: Pearson Education do Brasil, 2013.

CHIAVENATO, Idalberto. Gestão de vendas: uma abordagem introdutória: transformando um profissional de vendas em um gestor de vendas. Barueri, SP: Manole, 2014.

CHURCHILL, Jr. Gilbert A.; PETER J. Paul. Marketing: criando valor para os clientes. São Paulo: Saraiva, 2012.

FUTRELL Charles M. Vendas: fundamentos e novas práticas de gestão. São Paulo: Saraiva, 2003.

GARCIA Janaína Leonardo. Marketing de serviços e de varejo. São Paulo: Pearson Education do Brasil, 2015.

GIL, Antônio Carlos. Como elaborar projetos de pesquisa. São Paulo: Atlas, 2009.

KAUARK Fabiana da S.; MANHÃES Fernanda C; MEDEIROS Carlos $\mathrm{H}$. Metodologia depesquisa: um guia prático. Itabuna/Ba : Via Litteraraum, 2010.

KOTLER, Philip. Administração de marketing: análise, planejamento,implementação e controle. São Paulo: Atlas, 1998.

KOTLER Philip. Marketing essencial: conceitos, estratégias e casos. São Paulo: Prentice Hall, 2005.

KOTLER Philip; ARMSTRONG Gary. Princípios de marketing. São Paulo: Pearson

$\mathrm{e}^{3}$ - Revista de Economia, Empresas e Empreendedores na CPLP | Volume 4 | Número 1 
Education do Brasil, 2015.

KOTLER Philip; KELLER Kevin Lane. Administração de marketing: a bíblia do marketing. São Paulo: Pearson Prentice Hall, 2006.

MARCONI, Marina de Andrade; LAKATOS, Eva Maria. Fundamentos de metodologia científica. São Paulo: Atlas, 2005.

MARCONI, Marina de Andrade; LAKATOS, Eva Maria. Técnicas de pesquisa: planejamento e execução de pesquisa; Amostragens de técnicas de pesquisa; elaboração, análise e interpretação de dados. São Paulo: Atlas, 2002.

SAMARA Beatriz Santos; BARROS José Carlos de. Pesquisa de marketing: conceitos e metodologia. São Paulo: Pearson Prentice Hall, 2006.

SAMARA Beatriz Santos; MORSCH Marco Aurélio. Comportamento do consumidor: conceitos e casos. São Paulo: Prentice Hall, 2005.

VERGARA, Sylvia Constant. Métodos de pesquisa em administração. São Paulo: Atlas, 2008.

VERGARA, Sylvia Constant. Projetos e relatórios de pesquisa em administração. Rio de Janeiro: Atlas, 2000.

\section{(c) BY-NC-SA}

O trabalho $\mathrm{e}^{3}$ - Revista de Economia, Empresas e Empreendedores na CPLP está licenciado com uma Licença Creative Commons - Atribuição-NãoComercial-Compartilha Igual 4.0 Internacional. 